\title{
A study of knowledge about immunization amongst mothers of children below 5 years of age
}

\author{
Ramawat $\mathbf{P}^{1}$, Goswami $V P^{2}$ \\ ${ }^{1}$ Dr. Pramila Ramawat, Assistant Professor, Department of Paediatrics, Index Medical College and Hospital and Research \\ Centre Indore, ${ }^{2}$ Dr. V. P. Goswami, Assistant Professor, Department of Community Medicine, Index Medical College \\ and Hospital and Research Centre Indore, MP, India.
}

Corresponding Author: Dr. V. P. Goswami, Assistant Professor, Department of Community Medicine, Index Medical College and Hospital and Research Centre Indore. Email id: drvpgoswami@gmail.com

\begin{abstract}
Objectives: To assess the knowledge and attitude of mothers regarding immunization of children below 5 years of age. Methodology: A cross sectional descriptive study was conducted among mothers having children below 5 years of age. All mothers were interviewed through a self-designed pretested structured questionnaire regarding immunization of their children and socio demographic profile. Results: Majority of the mothers were illiterate, belonging to low-income group and not awareabout the diseases in national immunization program. Majority $(77 \%)$ of children were completely immunized according to age. The reasons for incomplete vaccination were lack of awareness, knowledge, distance, cough, cold and others reasonslike household work. Anganwadi workers and health care workers were the main source of information. A positive attitude was reflected from mother towards immunization. Conclusion: The knowledge of mothers about vaccination was found inadequate but attitude toward immunization was good.
\end{abstract}

Key Words: Immunization, Mothers Knowledge, Attitude and practice.

\section{Introduction}

Every year nearly 2 million children are dying before their $5^{\text {th }}$ birth day [1]. In 2010 it was estimated that 1.7 million children died from vaccine preventable diseases. It was also noted that 19.3 million children had been incompletely vaccinated, leaving them susceptible to vaccine preventable disease related mortality and morbidity. Approximately $50 \%$ of all under vaccinated children live in three countries, India being one of them $[2,3]$. Immunization is very efficient, cost effective and beneficial way to save children from many vaccine preventable diseases.

Prevention is always best method of protection. WHO had launched in 1974, an expanded Program of immunization (EPI) against 6 vaccine preventable diseases (VPD) to reduce childhood mortality and morbidity i.e. BCG, DPT, OPV, TT. In India it was started in 1978. Now with help of WHO, Immunization Program is running successfully all over countryand many newer vaccines included in program, polio is already eradicated successfully. Inspite of that in most

Manuscript received: $10^{\text {th }}$ March 2018

Reviewed: $20^{\text {th }}$ March 2018

Author Corrected: $26^{\text {th }}$ March 2018

Accepted for Publication: $31^{\text {st }}$ March 2018 of areas in country immunization coverage is lacking. Many factors are responsible for it - difficulty in accessibility, distance to center, false beliefs but most important factor is lack of awareness about benefits of immunization in remote areas where illiteracy, poverty and distance to health care facilities are still major issues. Any social program success determined by awareness among people, their favorable attitude and willingness to involve in activities. Mothers have most important role in child care, so their awareness and involvement is a necessity to implement programs for child's wellbeing. Mothers with sufficient knowledge, favorable attitude and healthy practices toward child's overall development aregood assets for our country.

Our objective for this study is to know knowledge of mothers about immunization and their attitude towards it. We also try to find out causes of incomplete immunization.

\section{Material \& Method}

A cross sectional study was conducted in rural medical college of Indore between September to October 2017. 
Mothers of children age below 5 year attending pediatrics OPD were included in the study. Well informed written consent was taken by all mothers, Mothers with older children and non-willing to participate were excluded.

During study 200 mothers were interviewed through a self-designed pre-tested structured questionnaire based on extensive literature search and WHO guidelines. The questionnaire included socio-demographic variables, immunization status of the children, reasons for incomplete immunization, any adversereaction, vaccination cards, their knowledge about vaccination, its schedule, benefits and diseases prevented by it, place of vaccination and their attitude towards vaccination. Total thirty questions were asked in interview. The questions had single as well as multiple correct options, some were open ended and others were with options all questions asked by doctors after explaining mother about study.

Statistical analysis - Statistical analysis was done by using descriptive and inferential statistics using chi square test. Software used in analysis was SPSS 20.0 version. $\mathrm{P}$ Value $<0.05$ is considered as level of significance.

\section{Observation \& Results}

In our study all children received immunization, $77 \%$ were completely immunized rest were incompletely immunized. Our findings revealed lack of knowledgeof mothers regarding immunization ofchild which leads to incomplete immunization status of child. All mothers belong to low socio economic status, majority were laborer, theywork on farms and most of them with monthly family income less than $10000 \mathrm{Rs} / \mathrm{month}$.

Demographic Profile- In our study most of mothers did not have sufficient knowledge of immunization and it associated with lack of knowledge to mother's education, income, age and number of children.

Table-01: Comparison of mother's Knowledge about Immunization under various demographic variables

\begin{tabular}{|c|c|c|c|c|c|}
\hline \multirow{2}{*}{ Age of mother } & \multirow{2}{*}{$\begin{array}{c}\text { No. of mother } \\
(\mathbf{n = 2 0 0 )}\end{array}$} & \multicolumn{3}{|c|}{ Knowledge of mother about immunization } & \multirow{2}{*}{ P-Value } \\
& & Genefits & \\
\cline { 2 - 5 } & 113 & 3 & 61 & 49 & \multirow{2}{*}{0.018} \\
\hline Below 25 year & 87 & 3 & 71 & 13 & \\
\hline 25years and above & & & Pood & & \\
\hline
\end{tabular}

\begin{tabular}{|c|c|c|c|c|c|}
\hline \multirow{2}{*}{ Income / month } & \multirow{2}{*}{$\begin{array}{c}\text { Number of } \\
\text { mothers }\end{array}$} & \multicolumn{3}{|c|}{ Knowledge of mothers about immunization } & P-Value \\
& $(\mathbf{n = 2 0 0 )}$ & Good & Average & Poor & \\
\cline { 2 - 5 } & 27 & 5 & 16 & 6 & 0.022 \\
\hline Above 10,000 Rs & 173 & 1 & 116 & 56 & \\
\hline Below 10000 Rs & & &
\end{tabular}

\begin{tabular}{|c|c|c|c|c|c|}
\hline \multirow[t]{2}{*}{ Education of mothers } & \multirow[t]{2}{*}{$\begin{array}{l}\text { Number of mothers } \\
\qquad(\mathbf{n}=\mathbf{2 0 0})\end{array}$} & \multicolumn{3}{|c|}{$\begin{array}{c}\text { Knowledge of mothers about immunization } \\
\text { benefits }\end{array}$} & \multirow[t]{2}{*}{ P-Value } \\
\hline & & Good & Average & Poor & \\
\hline Primary & 16 & 4 & 92 & 11 & \multirow[t]{2}{*}{0.038} \\
\hline Illiterate & 184 & 2 & 40 & 51 & \\
\hline
\end{tabular}

\begin{tabular}{|c|c|c|c|c|c|}
\hline Number of children & $\begin{array}{c}\text { Number of mothers } \\
(\mathbf{n = 2 0 0 )}\end{array}$ & \multicolumn{3}{|c|}{$\begin{array}{c}\text { Knowledge of mothers about } \\
\text { immunizationbenefits }\end{array}$} & P-Value \\
\cline { 3 - 5 } & & Good & Average & Poor & \multirow{2}{*}{0.016} \\
\hline One child & 46 & 1 & 13 & 32 & 30 \\
\hline More than one child & 154 & 5 & 119 & \\
\hline
\end{tabular}


Most of mothers were illiterate (92\%), some were educated upto primary level but did not know about importance of immunization and serious diseases prevented by it, immunization schedule, new and routine vaccines. They all kept immunization card well and knew its importance in vaccination. All mothers were received tetanus toxoid in pregnancy and delivered in hospital. First vaccination in most of cases was provided in hospitals, rest of immunization covered at Anganwadi level in $86 \%$ children. In our study $77 \%$ children were completely immunized till date while $23 \%$ received incomplete immunization, causes of delay were mild illnesses, busy in work, distance, forget next date for vaccination. Most of mother told that next date for vaccination was given and explained by Anganwadi workers.

Table-02: Concerns of Mothers about Immunization

\begin{tabular}{|c|c|c|c|}
\hline Response of mothers & Good & Average & Poor \\
\hline Vaccine given & $23 \%$ & $77 \%$ & $71 \%$ \\
\hline Disease prevented by it & $8 \%$ & $21 \%$ & $31 \%$ \\
\hline Immunization schedule & $3 \%$ & $66 \%$ & $2 \%$ \\
\hline Use of Immunization card & $56 \%$ & $42 \%$ & $53 \%$ \\
\hline Importance of vaccine & $13 \%$ & $34 \%$ & 0 \\
\hline
\end{tabular}

Majority of mothers (81\%) like and showed favorable attitude towardsimmunization program. No mother told about any serious adverse reaction after vaccination to their child, some gave history of fever after vaccination but medication already given to them by health workers and they were well informed about it.In our study most ofmothersdid not know about benefits of immunization in spite of that showed positive attitudestowards vaccination.

\section{Discussion}

Our study reported limited knowledge of mothers about vaccine preventable diseases and similar findings have been reported from studies conducted in other places [4,5]. Assessment of knowledge of mothers about immunization showed association with lack of education and low socioeconomic status and age. When the socio demography was assessed, a low literacy level was found in these rural motherswho are mostly house wives belongs to lower socio economical class.

This was significant and needs to be addressed in order to improve implementation of immunization program and better coverage, as most mothers are the primary caretakers and decision makers regarding vaccination in their families. Singh et al had reported in their study that mothers had fair knowledge regarding the need for immunization but had poor knowledge regarding VPDs [6]. In a study by Kapoor et al it was found that awareness and knowledge about VPDs increases with education status of mothers [7].

In a cross-sectional study conducted by Siddiqui et alinurban Karachi significantly better vaccination status was found among children with both parent's literate as compared to children with bothparents illiterate [8]. study conducted in Sydney during 1999 reported that, in their support for vaccination, parents not only valued the benefits of protecting their own individual child but mothers from a range of socioeconomic and educational backgrounds also understood and appreciated the social nature of the vaccination decision [11]. Our study revealed that Anganwadi workers were the main source of information in the rural areas and very helpful in implementing various heath program in rural community. This was in concordance with the study by Manjuath et al [10].

In our study health care workers specially Anganwadi workers were the main source of information for mothers and providing immunization coverage to their children at proper time. Similar findings have been reported from other parts of our country and other countries like Pakistan and Bangladesh where nurses and other paramedical workers were mentioned as the main sources of information about immunization for slumwomen $[4,6,9]$. In our study major reasons for incomplete immunization were - lack of time for vaccination due to work, minor illnesses, distance from center and forget next date due to lack of awareness.

Similar findings from developed and developing $[4,6]$. countries have reported mild diseases as a reason for deferring immunization.

Vaccination cards are consi-dered to be the important source of immunization coverage record keeping and most of mothers knew it.In a similar KAP study $76 \%$ of mothers were aware of the use and the necessity to save Immunization cards [9]. According to our study low socioeconomic status, lack of education and awareness in rural area are major factors responsible for less 
immunization coverage but good efforts by health care workers specially Anganwadi workers try to fill the gap.

\section{Conclusion}

Our study concluded that the knowledge of mothers about vaccination was found inadequate with positive attitude towards vaccination. Reasons behind this lack of knowledge are low socioeconomic status, lack of education and lack of awareness in rural population regarding benefits of immunization. Inspite of that coverage is better which suggested strong role of health care workers specially Anganwadi workers in providing immunization.

If awareness among rural mothers about vaccine's benefits improve then immunization coverage will improve drastically. There is a felt need to impart four key messages to beneficiaries while giving vaccines to address this gap.

Funding: Nil, Conflict of interest: None initiated, Perission from IRB: Yes

\section{References}

1. Jose J, Lobo MR, Nisha K, Shilpa GS, Umarani J. Awareness on Immunization among Mothers of Underfive Children. Int J Inov. Res. Develop. 2013; 2: 620-7.

2. Global immunization data. http://www.who.int/ immunization_monitoring/Global_Immunization_Data. pdf as accessed on 24- 1-2012.

3.Weekly Epidemiological Record No.46, 2011, 86, 509- 520 http:// www.who.int/wer/2011/wer8646.pdf as accessed on 24-1-2012.

4. Nath B, Singh JV, Awasthi S, Bhushan V, Kumar V, Singh SK. KAP Study on immunization of Children in a
City of North India- A 30 Cluster Survey. OJHAS 2008; 7(1): 2-10.

5. Management Group, Medical Center, Birla Institute of Technology and Science (BITS), Pilani. Maternal knowledge and perceptions about the routine immunization programme- a study in a semiurban area in Rajasthan. 2003; 57(4): 158-63.

6. Nisar N, Mirza M, Qadri MH. Knowledge, attitude and practices of mothers regarding immunization of one year old child at Mawatch Goth, Kemari town, Karachi Pakistan. Pak J Med Sci. 2010; 26(1): 183-90.s

7. Singh $\mathrm{MC}$, Badole $\mathrm{CM}$, Singh MP. Immunization coverage and the knowledge and practice of mothers regarding immunization in rural area. Indian J Public Health. 1994 Jul-Sep;38(3):103-7.

8. Kapoor R and Vyas S. Awareness and Knowledge of mothers of under five children regarding immunization in Ahmedabad. Healthline 2010;1(1):12-15.

9. Siddiqui N, Siddiqi AE, Nisar $\mathrm{N}$ and Khan A. Mothers knowledge about EPI and its relation with age - appropriate vaccination of infants in peri-urban Karachi. J Pak Med Assoc 2010; 60(11):940- 944.

10. Manjunath U, Pareek RP. Maternal knowledge and perceptions aboutthe routine immunization programme-a studyin asemiurbanarea in Rajasthan.Indian J Med Sci. 2003 Apr;57(4):158-63.

11. Leask J, Chapman S, Hawe P, Burgess M. What maintains parental support for vaccination when challenged by anti-vaccination messages? A qualitative study. Vaccine. 2006 Nov 30; 24(49-50):7238-45. Epub 2006 May 23.

\section{How to cite this article?}

Ramawat P, Goswami VP. A study of knowledge about immunization amongst mothers of children below 5 years of age.Int J Pediatr Res. 2018;5(3):109-112. doi:10.17511/ijpr.2018.103.01. 